\title{
EVALUATION OF METHODS FOR ESTIMATING FATIGUE PROPERTIES APPLIED TO STAINLESS STEELS AND ALUMINUM ALLOYS
}

Taylor Mac Intyer Fonseca Junior ' Rodrigo Magnabosco ${ }^{2}$

\begin{abstract}
This work evaluate seven estimation methods of fatigue properties applied to stainless steels and aluminum alloys. Experimental strain-life curves are compared to the estimations obtained by each method. After applying seven different estimation methods at 14 material conditions, it was found that fatigue life can be estimated with good accuracy only by the Bäumel-Seeger method for the martensitic stainless steel tempered between $300^{\circ} \mathrm{C}$ and $500^{\circ} \mathrm{C}$. The differences between mechanical behavior during monotonic and cyclic loading are probably the reason for the absence of a reliable method for estimation of fatigue behavior from monotonic properties for a group of materials.
\end{abstract}

Key words: Strain-controlled fatigue; Fatigue lige; Stainless steel; Aluminum alloys.

\section{INTRODUCTION}

Monotonic mechanical properties can be easily obtained at tension tests, with great accuracy. The most important variables extracted from a monotonic stress-strain curve that characterize the monotonic mechanical behavior are Young's modulus $(E)$, yield strength $\left(Y_{s}\right)$, ultimate tensile strength $\left(T_{s}\right)$, total elongation (TE), area reduction at fracture (AR), true fracture stress $\left(\sigma_{F}\right)$ and strain $\left(\varepsilon_{\mathrm{F}}\right)$, strength coefficient $(\mathrm{H})$ and strain-hardening exponent ( $n$ ) of the Ramberg-Osgood equation (Equation I): (I)

$$
\varepsilon=\varepsilon_{E}+\varepsilon_{P}=\frac{\sigma}{E}+\left(\frac{\sigma}{H}\right)^{\frac{1}{n}}
$$

where $\varepsilon$ is the total strain applied during monotonic loading, $\varepsilon_{\mathrm{E}}$ is the elastic strain and $\varepsilon_{\mathrm{p}}$ is the plastic strain. When a metal is cyclically loaded, a modification of the Ramberg-Osgood is valid:

$$
\frac{\Delta \varepsilon_{\mathrm{T}}}{2}=\frac{\Delta \varepsilon_{\mathrm{E}}}{2}+\frac{\Delta \varepsilon_{\mathrm{P}}}{2}=\frac{\Delta \sigma}{2 \mathrm{E}}+\left(\frac{\Delta \sigma}{2 \mathrm{H}^{\prime}}\right)^{\frac{1}{\mathrm{n}^{\prime}}}
$$

where $\Delta \varepsilon_{T} / 2$ is the total strain amplitude applied during cyclic loading, $\Delta \varepsilon_{\mathrm{E}} / 2$ is the elastic strain amplitude and $\Delta \varepsilon_{\mathrm{p}} / 2$ is the plastic strain amplitude. From this equation, the cyclic strength coefficient $\left(\mathrm{H}^{\prime}\right)$ and cyclic strain-hardening exponent ( $\left.n^{\prime}\right)$ can be defined, allowing the comparison between monotonic and cyclic mechanical behaviors.
Metallic materials present cyclic hardening when the cyclic stress-strain curve described by Equation 2 shows higher stress values in a specific strain level when compared to those predicted by Equation I. However, cyclic softening or a mixed behavior could also be observed. Hertzberg(2) relates the tendency of a given material to undergo cyclic hardening or softening to the quotient $T_{s} Y_{s}$ : if the quotient is higher than I.4, cyclic hardening was expected, and when the quotient is lower than I.2, cyclic softening is the most common behavior observed. In the same way, there is a tendency to observe cyclic hardening if the monotonic strain-hardening exponent $(\mathrm{n})$ is higher than 0.2 ; cyclic softening can be observed if $\mathrm{n}$ is lower than 0.1.

During cyclic loading, fatigue failure can occur, and for mechanical design the determination of the fatigue life under an applied load is desired. Strain-controlled fatigue tests can generate strain-life fatigue curves, which can be generally described by:

$$
\frac{\Delta \varepsilon_{T}}{2}=\frac{\Delta \varepsilon_{E}}{2}+\frac{\Delta \varepsilon_{P}}{2}=C_{E} \cdot\left(N_{F}\right)^{b}+C_{P} \cdot\left(N_{F}\right)^{c}
$$

where $N_{F}$ is the number of cycles to failure, the elastic term of the total strain imposed can be described by the elastic coefficient $\left(C_{E}\right)$ and the fatigue strength exponent (b), and the plastic term is described by the plastic coefficient $\left(C_{p}\right)$ and by the fatigue strain exponent $(c){ }^{(3)}$

'Assistant Professor, Department of Material Engineering, Ignatian Educational Foundation - FEl, Av. Humberto A. C. Branco, 3972 , 
Cyclic and fatigue tests are more time-consuming than monotonic tension tests, leading to great availability of monotonic properties. This naturally leads to the development of methods for the estimation of fatigue properties from monotonic ones. ${ }^{(4)}$ This work analyzes seven estimation methods, described in the following topics.

Four-point method (4P): this method received this name because it uses two points to determine the elastic term of the strain-life curve (in a log-log plot), and other two for the plastic term. ${ }^{(5)}$ Algebraically, it can be described by:

$$
\frac{\Delta \varepsilon_{\mathrm{T}}}{2}=\mathrm{C}_{\mathrm{E}_{(4 \mathrm{P})}} \cdot\left(\mathrm{N}_{\mathrm{F}}\right)^{\mathrm{b}(4 \mathrm{PP})}+\mathrm{C}_{\mathrm{P}_{(4 \mathrm{P})}} \cdot\left(\mathrm{N}_{\mathrm{F}}\right)^{\mathrm{C}_{(4 \mathrm{P})}}
$$

where:

$$
\begin{aligned}
& \mathrm{b}_{(4 \mathrm{P})}=-0.1785 \cdot \log \left[2.78\left(1+\varepsilon_{\mathrm{F}}\right)\right] \\
& \mathrm{M}_{1}=\frac{\mathrm{T}_{\mathrm{S}}}{\mathrm{E}} \\
& \mathrm{M}_{2}=\log \left[2.5 \cdot \mathrm{M}_{1}\left(1+\varepsilon_{\mathrm{F}}\right)\right] \\
& \mathrm{C}_{\mathrm{E}_{(4 \mathrm{P})}}=\frac{1}{2} \cdot 10^{0.301 \mathrm{~b}_{(4 \mathrm{P})}+\mathrm{M}_{2}} \cdot 2^{\mathrm{b}_{(4 \mathrm{P})}} \\
& \mathrm{M}_{3}=10^{4.602 \cdot \mathrm{b}_{(4 \mathrm{P})}+\mathrm{M}_{2}} \\
& \mathrm{M}_{4}=\log \left(0.25 \cdot \varepsilon_{\mathrm{F}}^{0.75}\right) \\
& \mathrm{C}_{(4 \mathrm{P})}=0.333 \cdot\left[\log \left(0.00691-0.52356 \cdot \mathrm{M}_{3}\right)-\mathrm{M}_{4}\right]( \\
& \mathrm{C}_{\mathrm{P}_{(4 \mathrm{P})}}=\frac{1}{2} \cdot 10^{-1.301 \mathrm{C}_{(4 \mathrm{P})}+\mathrm{M}_{4}} \cdot 2^{\mathrm{C}_{(4 \mathrm{P})}}
\end{aligned}
$$

Universal slopes (US): this method fixed the elastic and plastic slopes, related to the fatigue strength and strain exponents ( $b$ and $c$ ) at -0.12 and -0.6 , respectively. ${ }^{(6)}$ This leads to:

$$
\frac{\Delta \varepsilon_{\mathrm{T}}}{2}=\mathrm{C}_{\mathrm{E}_{(\mathrm{U})}} \cdot\left(\mathrm{N}_{\mathrm{F}}\right)^{-0.12}+\mathrm{C}_{\mathrm{P}_{(\mathrm{U})}} \cdot\left(\mathrm{N}_{\mathrm{F}}\right)^{-0.6}
$$

where

$$
\mathrm{C}_{\mathrm{E}_{(\mathrm{U})}}=1.75 \cdot \mathrm{M}_{1}
$$

$$
\mathrm{C}_{\mathrm{P}_{(\mathrm{U})}}=0.5 \cdot \varepsilon_{\mathrm{F}}^{0.6}
$$

Mitchell method (Mit): also known as Socie et al method, is developed for steels with hardness below $500 \mathrm{HB}^{(3)}$ It is assumed that fatigue strength coefficient is numerically equal to the true fracture stress, and the fatigue strain coefficient can be assumed as the total strain at fracture. The fatigue strain exponent is again fixed at -0.6 , resulting in:

$$
\frac{\Delta \varepsilon_{\mathrm{T}}}{2}=\mathrm{C}_{\mathrm{E}_{(\mathrm{Mit})}} \cdot\left(\mathrm{N}_{\mathrm{F}}\right)^{\mathrm{b}}+\mathrm{C}_{\mathrm{P}_{(\mathrm{Mit})}} \cdot\left(\mathrm{N}_{\mathrm{F}}\right)^{-0.6}
$$

where

$$
C_{E_{(M t)}}=M_{5} \cdot 2^{b_{(M t)}}
$$

$$
M_{5}=\frac{\sigma_{F}}{E}
$$

$$
\begin{aligned}
& b_{(\text {Mit) }}=-\frac{1}{6} \log \left(\frac{2 \cdot M_{5}}{M_{1}}\right) \\
& C_{P_{(M i t)}}=0.66 \cdot \varepsilon_{F}
\end{aligned}
$$

Bäumel-Seeger method: two different sets of equations are used in this method. ${ }^{(3)}$ For low-alloy and carbon steels, generally called ferrous materials, the main expression $\left(\mathrm{BS}_{\mathrm{F}}\right)$ is:

$$
\frac{\Delta \varepsilon_{\mathrm{T}}}{2}=\mathrm{C}_{\mathrm{E}_{(\mathrm{BS})}} \cdot\left(\mathrm{N}_{\mathrm{F}}\right)^{-0.087}+\mathrm{C}_{\mathrm{P}_{(\mathrm{BSF})}} \cdot\left(\mathrm{N}_{\mathrm{F}}\right)^{-0.58}
$$

where

$$
\begin{aligned}
& \mathrm{C}_{\mathrm{E}_{\left(\mathrm{BS}_{\mathrm{F}}\right)}}=1.412 \cdot \mathrm{M}_{1} \\
& \mathrm{C}_{\mathrm{P}_{(\mathrm{BSF})}}=0.395 \cdot \mathrm{M}_{6}
\end{aligned}
$$

considering that $M_{6}=1$ if $M_{1} \leq 0.003$ and $M_{6}=1.375-125 \cdot M_{1}$ if $M_{1}>0.003$. For non-ferrous alloys (specifically aluminum or titanium alloys), the method $\left(\mathrm{BS}_{\mathrm{N}}\right)$ is described by:

$$
\frac{\Delta \varepsilon_{\mathrm{T}}}{2}=\mathrm{C}_{\mathrm{E}_{(\mathrm{BS})}} \cdot\left(\mathrm{N}_{\mathrm{F}}\right)^{-0.095}+0.217 \cdot\left(\mathrm{N}_{\mathrm{F}}\right)^{-0.69}
$$

where

$$
\mathrm{C}_{\mathrm{E}_{\left(\mathrm{BS}_{\mathrm{N}}\right)}}=1.564 \cdot \mathrm{M}_{1}
$$


Modified four-point method (4PM): Ong(5) proposes some modifications to the previously discussed four-point method for a better fit to experimental fatigue data of steels. The estimation of the strain-life curve is possible through:

$$
\frac{\Delta \varepsilon_{\mathrm{T}}}{2}=\mathrm{C}_{\mathrm{E}_{(4 \mathrm{PM})}} \cdot\left(\mathrm{N}_{\mathrm{F}}\right)^{\mathrm{b}_{(4 \mathrm{PM})}}+\mathrm{C}_{\mathrm{P}_{(4 \mathrm{PM})}} \cdot\left(\mathrm{N}_{\mathrm{F}}\right)^{\mathrm{C}_{(4 \mathrm{PM})}}
$$

where

$$
\begin{aligned}
& \mathrm{b}_{(4 \mathrm{PM})}=\frac{1}{6}\left[\log \left(0.16 \cdot \mathrm{M}_{5}^{0.81}\right)-\log \left(\mathrm{M}_{5}\right)\right] \\
& \mathrm{C}_{\mathrm{E}_{(4 \mathrm{PM})}}=\mathrm{M}_{5} \cdot 2^{\mathrm{b}_{(4 \mathrm{PM})}} \\
& \mathrm{M}_{7}=\mathrm{M}_{5} \cdot 10^{4 \cdot \mathrm{b}_{(4 \mathrm{PM})}} \\
& \mathrm{C}_{(4 \mathrm{PM})}=\frac{1}{4}\left[\log \left(0.00355-0.48216 \cdot \mathrm{M}_{7}\right)-\log \left(\varepsilon_{\mathrm{F}}\right)\right] \\
& \mathrm{C}_{\mathrm{P}_{(4 \mathrm{PM})}}=\varepsilon_{\mathrm{F}} \cdot 2^{\mathrm{c}_{(4 \mathrm{PM})}}
\end{aligned}
$$

Modified universal slopes method (MUS): some modifications on the previously described US method are proposed, ${ }^{(3)}$ allowing the estimation of the strain-life curve by:

$$
\frac{\Delta \varepsilon_{\mathrm{T}}}{2}=\mathrm{C}_{\mathrm{E}_{(\mathrm{MUS})}} \cdot\left(\mathrm{N}_{\mathrm{F}}\right)^{-0.09}+\mathrm{C}_{\mathrm{P}_{\text {(MUS) }}} \cdot\left(\mathrm{N}_{\mathrm{F}}\right)^{-0.56}
$$

where

$$
\mathrm{C}_{\mathrm{E}_{(\mathrm{Mus})}}=0.585 \cdot \mathrm{M}_{1}^{0.832}
$$

$$
\mathrm{C}_{\mathrm{P}_{\text {(MUS) }}}=0.0133 \cdot \varepsilon_{\mathrm{F}}^{0.155} \cdot \mathrm{M}_{1}^{-0.53}
$$

Morrow $^{(7)}$ also shows that fatigue strength and ductility exponents ( $b$ and c) can be estimated from cyclic strain hardening exponent ( $\mathrm{n}$ '), according to:

$$
b=\frac{-n^{\prime}}{1+5 n^{\prime}}
$$

$$
c=\frac{-1}{1+5 n^{\prime}}
$$

Re-arranging Equations 35 and 36 lead to:

$$
n^{\prime}=\frac{b}{c}
$$

Considering those facts, the main purpose of this work is the evaluation of the estimation methods presented, analyzing their applicability and accuracy in two duplex stainless steels (UNS S3 1803, also known as 2205, and UNS S32750, also known as 2507), a martensitic stainless steel UNS S42000 (quenched and tempered in seven different conditions, obtaining different strength

\begin{tabular}{|c|c|c|c|c|c|c|c|c|c|c|}
\hline Material & $\mathrm{Mg}$ & $M n$ & Si & $\mathrm{Fe}$ & Zn & $\mathrm{Cu}$ & $\mathrm{Cr}$ & $\mathrm{Ti}$ & Al & ID \\
\hline A4I3.0 & 0.08 & - & 10.94 & 0.17 & - & - & - & 0.120 & \multirow{5}{*}{ 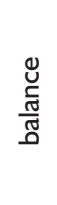 } & A4I3 \\
\hline A356.0 & 0.32 & - & 7.44 & 0.14 & - & - & - & 0.130 & & A356 \\
\hline AA7I75-TI & 2.32 & 0.02 & 0.09 & - & 5.13 & 1.400 & 0.180 & - & & 7175 \\
\hline AA626I-T6 & 0.68 & 0.26 & 0.31 & 0.33 & 0.03 & 0.130 & 0.002 & 0.007 & & 6261 \\
\hline AA635I-T6 & 0.59 & 0.43 & 0.44 & 0.28 & 0.02 & 0.006 & 0.001 & 0.006 & & 6351 \\
\hline
\end{tabular}
levels), two cast (A4I3.0 and A356.0) and three wrought (AA7I75-TI, AA626I-T6 and AA635I-T6) aluminum

\begin{tabular}{|c|c|c|c|c|c|c|c|c|c|}
\hline Material & C & $\mathrm{Cr}$ & $\mathbf{S i}$ & $\mathbf{N i}$ & Mn & Mo & $\mathbf{N}$ & $\mathbf{F e}$ & ID \\
\hline UNS S42000 & 0.380 & 12.28 & 0.45 & 0.14 & 0.52 & - & - & \multirow{3}{*}{ 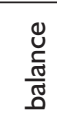 } & $M X X X^{*}$ \\
\hline UNS S31803 & 0.015 & 22.20 & 0.50 & 5.40 & 0.80 & 3.2 & 0.18 & & 2205 \\
\hline UNS S32750 & 0.015 & 25.00 & 0.30 & 6.90 & 0.40 & 3.8 & 0.26 & & 2507 \\
\hline
\end{tabular}
alloys. Experimental strain-life curves are compared to the estimated strain-life curves obtained by each presented method.

\section{EXPERIMENTAL}

Cast aluminum samples were obtained by low-pressure die casting, and the wrought aluminum alloys and stainless steels were obtained from commercial round bars of approximately $20 \mathrm{~mm}$ diameter. Tables I and 2

Table I. Chemical composition (wt\%) of the studied aluminum alloys, and identification (ID) used

Table 2. Chemical composition (wt\%) of the studied stainless steels, and identification (ID) used

* MXXX indicates tempering temperature in ${ }^{\circ} \mathrm{C}$ for martensitic stainless steels. 
show the chemical composition (wt\%) of the studied materials. While duplex stainless steels presents only solution-treated structures, martensitic stainless steels were oil quenched from $1000^{\circ} \mathrm{C}$ and then tempered for I hour at $200^{\circ} \mathrm{C}, 300^{\circ} \mathrm{C}, 400^{\circ} \mathrm{C}, 450^{\circ} \mathrm{C}, 500^{\circ} \mathrm{C}, 550^{\circ} \mathrm{C}$ or $600^{\circ} \mathrm{C}$, to obtain different strength levels. Wrought aluminum alloys are solution-treated and naturally aged (AA7 175-TI alloy) or artificially aged (AA626I-T6 and AA635I-T6 alloys).

Tension tests following ASTM E8M(8) were conducted in a servo-hydraulic MTS 810.25 testing machine. For each material were determined: Young's modulus $(E)$, yield strength $\left(Y_{s}\right)$, ultimate tensile strength $\left(\mathrm{T}_{\mathrm{s}}\right)$, total elongation in $25 \mathrm{~mm}\left(\mathrm{TE}^{25}\right)$, reduction of area (RA), true fracture stress $\left(\sigma_{\mathrm{F}}\right)$, true fracture strain $\left(\varepsilon_{\mathrm{F}}\right)$, strength coefficient $(\mathrm{H})$ and strain-hardening exponent (n). In the same testing machine, strain-controlled fatigue tests were conducted according to ASTM E606, ${ }^{(9)}$ with a maximum test frequency of $0.5 \mathrm{~Hz}$ to avoid heating of the specimens during cyclic loading, and strain ratio $R=-I$, with application of load with sinusoidal wave. From the cyclic tests, the following properties are determined: fatigue strength (b) and ductility (c) exponents, elastic $\left(C_{E}\right)$ and plastic $\left(C_{p}\right)$ coefficients, cyclic strength coefficient $\left(\mathrm{H}^{\prime}\right)$ and cyclic strain-hardening exponent ( $\left.n^{\prime}\right)$.

\section{RESULTS}

Tables 3 and 4 summarize the monotonic mechanical properties extracted from tension tests. Fatigue properties are shown in Table 5. Using Equation I and 2 and the data of Tables 4 and 5, the true stress-strain curves for both monotonic and cyclic loadings are plotted, and Figure I shows typical behavior of selected materials. All of the aluminum alloys present cyclic hardening

Table 3. Monotonic mechanical properties of the studied materials

\begin{tabular}{cccccc}
\hline Material & $\mathbf{E}[\mathrm{GPa}]$ & $\mathbf{Y}_{\mathbf{S}}[\mathrm{MPa}]$ & $\mathbf{T}_{\mathbf{S}}[\mathrm{MPa}]$ & $\mathbf{A R}[\%]$ & TE $^{25}[\%]$ \\
\hline A413 & $65 \pm \mathrm{I}$ & $73 \pm 16$ & $169 \pm 21$ & $15.0 \pm 5.5$ & $11.8 \pm 3.1$ \\
A356 & $70 \pm 2$ & $220 \pm 20$ & $292 \pm 16$ & $11.8 \pm 1.2$ & $10.8 \pm 2.0$ \\
7175 & $71 \pm 2$ & $611 \pm 6$ & $656 \pm 10$ & $13.2 \pm 2.5$ & $10.0 \pm 1.3$ \\
6261 & $69 \pm 1$ & $278 \pm 10$ & $305 \pm 4$ & $61.0 \pm 1.7$ & $25.7 \pm 1.8$ \\
6351 & $68 \pm 3$ & $331 \pm 15$ & $355 \pm 10$ & $50.4 \pm 0.8$ & $20.4 \pm 3.1$ \\
2205 & $179 \pm 6$ & $532 \pm 10$ & $767 \pm 8$ & $84.1 \pm 1.2$ & $58.5 \pm 2.8$ \\
2507 & $198 \pm 1$ & $613 \pm 3$ & $862 \pm 3$ & $75.4 \pm 1.1$ & $55.6 \pm 1.5$ \\
M200 & $205 \pm 1$ & $1576 \pm 10$ & $2107 \pm 120$ & $3.0 \pm 0.7$ & $2.2 \pm 0.9$ \\
M300 & $212 \pm 2$ & $1509 \pm 130$ & $1860 \pm 19$ & $32.6 \pm 1.8$ & $16.9 \pm 2.5$ \\
M400 & $214 \pm 2$ & $1394 \pm 10$ & $1760 \pm 12$ & $29.6 \pm 7.4$ & $16.7 \pm 1.6$ \\
M450 & $206 \pm 13$ & $1435 \pm 9$ & $1781 \pm 16$ & $32.7 \pm 7.2$ & $16.6 \pm 2.0$ \\
M500 & $209 \pm 3$ & $1380 \pm 49$ & $1757 \pm 17$ & $21.4 \pm 4.6$ & $13.3 \pm 2.7$ \\
M550 & $208 \pm 3$ & $1286 \pm 30$ & $1672 \pm 30$ & $13.9 \pm 3.9$ & $7.0 \pm 1.8$ \\
M600 & $213 \pm 3$ & $933 \pm 7$ & $1125 \pm 10$ & $47.1 \pm 0.4$ & $23.0 \pm 0.1$ \\
\hline
\end{tabular}

Table 4. True stress-strain monotonic mechanical properties of the studied materials

\begin{tabular}{ccccc}
\hline Material & $\sigma_{\mathrm{F}}[\mathrm{MPa}]$ & $\varepsilon_{\mathrm{F}}$ & $\mathbf{H}[\mathrm{MPa}]$ & $\mathbf{n}$ \\
\hline A4I3 & $178 \pm 16$ & $0.162 \pm 0.056$ & $373 \pm 46$ & $0.247 \pm 0.017$ \\
A356 & $325 \pm 18$ & $0.125 \pm 0.012$ & $351 \pm 37$ & $0.088 \pm 0.007$ \\
7175 & $718 \pm 8$ & $0.142 \pm 0.025$ & $869 \pm 3$ & $0.070 \pm 0.002$ \\
6261 & $402 \pm 7$ & $1.890 \pm 0.090$ & $252 \pm 12$ & $0.025 \pm 0.006$ \\
6351 & $408^{*}$ & $1.400 *$ & $297 *$ & $0.022 *$ \\
2205 & $1943 \pm 60$ & $1.840 \pm 0.010$ & $848 \pm 12$ & $0.056 \pm 0.001$ \\
2507 & $1633 \pm 67$ & $1.400 \pm 0.010$ & $4299 \pm 370$ & $0.062 \pm 0.001$ \\
M200 & $2160 \pm 135$ & $0.030 \pm 0.007$ & $2252 \pm 75$ & $0.160 \pm 0.133$ \\
M300 & $1977 \pm 65$ & $0.394 \pm 0.026$ & $2072 \pm 27$ & $0.069 \pm 0.003$ \\
M400 & $2015 \pm 92$ & $0.354 \pm 0.101$ & $2142 \pm 148$ & $0.062 \pm 0.001$ \\
M450 & $2000 \pm 49$ & $0.399 \pm 0.107$ & $2546 \pm 60$ & $0.064 \pm 0.140$ \\
M500 & $2048 \pm 79$ & $0.241 \pm 0.058$ & $3037 \pm 147$ & $0.094 \pm 0.008$ \\
M550 & $1767 \pm 60$ & $0.150 \pm 0.046$ & $1452 \pm 59$ & $0.136 \pm 0.077$ \\
M600 & $1398 \pm 37$ & $0.636 \pm 0.006$ & $0.069 \pm 0.007$ \\
\hline
\end{tabular}

*results from only one valid tension test. 
(Figures Ia, b), in agreement to Mitchell ${ }^{(10)}$ results for wrought aluminum alloys; however, it is reported ${ }^{(11)}$ a mixed behavior for the AA606I-T65I wrought aluminum alloy, indicating the difficult to determine a generalized behavior based on material type. The two duplex stainless steels present cyclic softening (Figure Ic shows the behavior of UNS S32750); martensitic stainless steels tempered at $200^{\circ} \mathrm{C}$ and $300^{\circ} \mathrm{C}$ present cyclic hardening; the other tempered samples show mixed behavior (as shown in Figure Id).
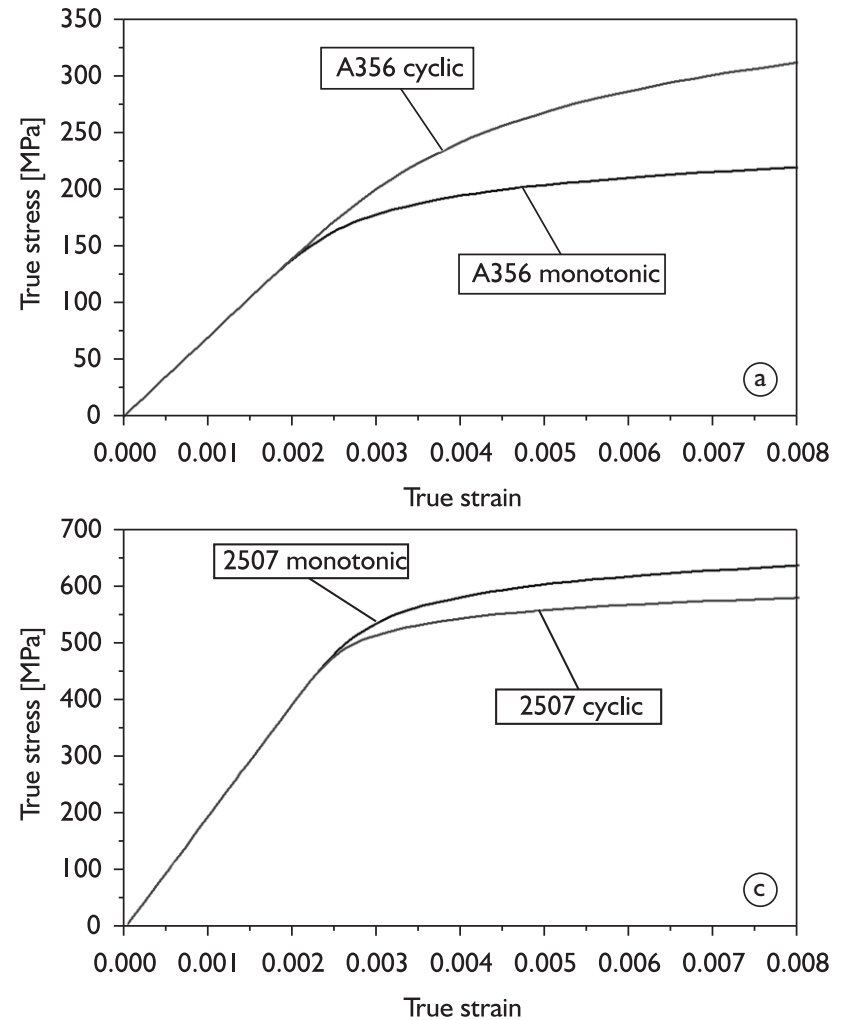

\section{DISCUSSION}

The use of Morrow Equations 35 to 37 to estimate b, $c$ and n' values leads to the data presented in Table 6. Those values can be compared to the experimental determined ones, presented in Table 5, using the relation:

$$
\frac{\Delta X}{X}=\frac{\left|X_{E X P}-X_{\text {Morrow }}\right|}{X_{E X P}} \times 100
$$
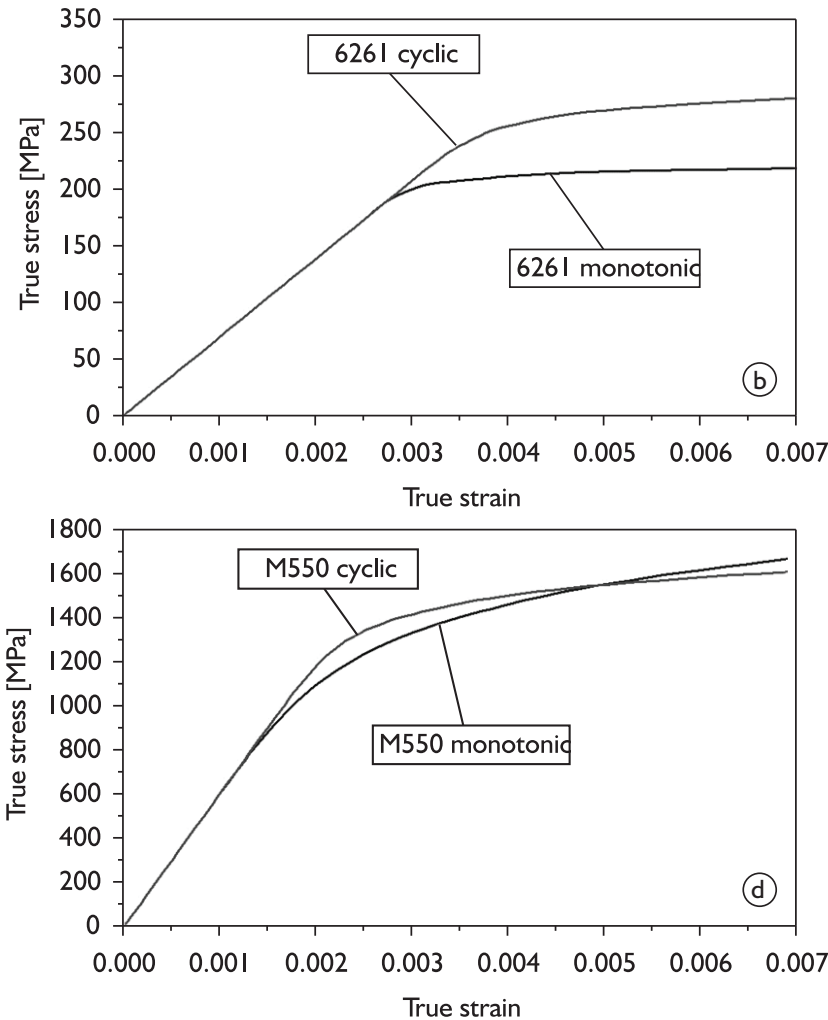

Figure I. Monotonic and cyclic stress-strain curves for: a) A356.0; b) AA626I-T6; c) UNS S32750; and d) martensitic stainless steels tempered at $550^{\circ} \mathrm{C}$.

Table 5. Cyclic mechanical properties of the studied materials

\begin{tabular}{|c|c|c|c|c|c|c|}
\hline Material & $C_{E}$ & b & $C_{p}$ & c & $\mathrm{H}^{\prime}[\mathrm{MPa}]$ & n' \\
\hline A4I3 & 0.002 & -0.057 & 2.633 & -0.887 & 128 & 0.028 \\
\hline A356 & 0.009 & -0.137 & 0.042 & -0.723 & 676 & 0.137 \\
\hline 7175 & 0.011 & -0.059 & 0.295 & -1.184 & 783 & 0.038 \\
\hline 6261 & 0.021 & -0.200 & 2.834 & -1.070 & 353 & 0.040 \\
\hline 6351 & 0.013 & -0.130 & 2.676 & -1.160 & 456 & 0.050 \\
\hline 2205 & 0.005 & -0.057 & 0.182 & -0.478 & 733 & 0.060 \\
\hline 2507 & 0.006 & -0.068 & 0.358 & -0.567 & 743 & 0.047 \\
\hline M200 & 0.017 & -0.134 & 0.023 & -0.880 & 4313 & 0.101 \\
\hline M300 & 0.012 & -0.082 & 0.530 & -0.867 & 2362 & 0.067 \\
\hline M400 & 0.013 & -0.090 & 0.460 & -0.818 & 2375 & 0.086 \\
\hline$M 450$ & 0.013 & -0.090 & 0.247 & -0.736 & 2377 & 0.079 \\
\hline M500 & 0.013 & -0.094 & 0.304 & -0.854 & 2094 & 0.053 \\
\hline M550 & 0.011 & -0.074 & 0.164 & -0.714 & 2157 & 0.067 \\
\hline M600 & 0.014 & -0.195 & 0.143 & -0.49 I & 4930 & 0.354 \\
\hline
\end{tabular}


where $X_{\text {EXP }}$ are the experimental value of b, $c$ or $n$ ' for a given material, and $X_{\text {Morrow }}$ is the estimated value. As showed in Table 6, only three predictions of the $c$ values present variations below $10 \%$, and the worst case shows a $367 \%$ difference of the estimated value of $n$ ' and the experimental result (AA626I aluminum alloy). Those data shows that Morrow relations (Equations 35 to 37) are not able to predict the desired fatigue properties for the studied materials.

According to Hertzberg,(2) if the quotient $\left(T_{S} Y_{S}\right)>1.4$, cyclic hardening was expected, and when $\left(\mathrm{T}_{\mathrm{s}} / Y_{\mathrm{s}}\right)<1.2$, cyclic softening is the most common behavior observed. In the same way, there is a tendency to observe cyclic hardening if the monotonic strain-hardening exponent $(n)$ is higher than 0.2 ; cyclic softening can be observed if $\mathrm{n}$ is lower than 0.1 . Using data from Tables 3 and 4 the predictions showed in Table 7 can be stated, showing that only A4I3.0 aluminum alloy and martensitic stainless steel tempered at $550^{\circ} \mathrm{C}$ could have their beha- vior accurately predicted (cyclic hardening and mixed, respectively). It can be concluded that the tendency of cyclic hardening or softening cannot be predicted from monotonic parameters.

Experimental strain-life curves and the seven estimated strain-life curves are shown in Figures 2 to 4 for the wrought aluminum alloy AA7I75-TI, the cast aluminum alloy A356.0, duplex stainless steel UNS S31803 and martensitic stainless steel UNS S42000 tempered at $600^{\circ} \mathrm{C}$ and $400^{\circ} \mathrm{C}$, respectively. Those five examples are chosen between the 14 materials studied to illustrate the most usual behaviors observed.

All the estimation methods leads to strain-life curves higher than experimental results of AA7I75-TI, as can be seen in Figure 2a, for a fatigue life up to $10^{4}$ cycles; for longer fatigue lifes, sub-estimation occurs. This behavior is also observed for the martensitic stainless steel tempered at $300^{\circ} \mathrm{C}$ or $550^{\circ} \mathrm{C}$.

Table 6. Estimated values of b, $c$ and n', and their variation to experimental values

\begin{tabular}{|c|c|c|c|c|c|c|}
\hline Material & $\mathbf{b}_{\text {Morrow }}$ & $\Delta \mathbf{b} / \mathbf{b}[\%]$ & $\mathbf{C}_{\text {Morrow }}$ & $\Delta \mathrm{c} / \mathrm{c}[\%]$ & $\mathbf{n}_{\text {Morrow }}$ & $\Delta n^{\prime} / n^{\prime}[\%]$ \\
\hline A4I3 & -0.025 & 57 & -0.877 & I & 0.064 & 130 \\
\hline A356 & $-0.08 \mathrm{I}$ & 41 & -0.593 & 18 & 0.189 & 38 \\
\hline 7175 & -0.032 & 46 & -0.840 & 29 & 0.050 & 31 \\
\hline 6261 & -0.033 & 83 & -0.833 & 22 & 0.187 & 367 \\
\hline 6351 & -0.040 & 69 & -0.800 & 31 & 0.112 & 124 \\
\hline 2205 & -0.046 & 19 & -0.769 & 61 & 0.119 & 99 \\
\hline 2507 & -0.038 & 44 & -0.810 & 43 & 0.120 & 155 \\
\hline$M 200$ & -0.067 & 50 & -0.664 & 25 & 0.153 & 51 \\
\hline M300 & -0.050 & 39 & -0.748 & 14 & 0.095 & 41 \\
\hline M400 & -0.061 & 33 & -0.697 & 15 & 0.111 & 27 \\
\hline M450 & -0.057 & 37 & -0.716 & 3 & 0.123 & 55 \\
\hline M500 & -0.042 & 55 & -0.788 & 8 & 0.110 & 105 \\
\hline M550 & -0.051 & 32 & -0.747 & 5 & 0.104 & 54 \\
\hline$M 600$ & -0.128 & 34 & $-0.36 \mathrm{I}$ & 27 & 0.397 & 12 \\
\hline
\end{tabular}

Table 7. Observed cyclic hardening or softening behavior and its predictions

\begin{tabular}{cccccc}
\hline \multirow{2}{*}{ Material } & Experimental & \multicolumn{2}{c}{$\left(\mathbf{T}_{\mathbf{s}} / \mathbf{Y}_{\mathbf{s}}\right)$ prediction } & \multicolumn{2}{c}{$\mathbf{n}$ prediction } \\
\cline { 3 - 6 } behavior & hardening & $\mathbf{T}_{\mathrm{s}} / \mathbf{Y}_{\mathbf{S}}$ & prediction & $\mathbf{n}$ & prediction \\
\hline A413 & hardening & 1.32 & hardening & 0.247 & hardening \\
A356 & hardening & 1.33 & mixed & 0.088 & softening \\
7175 & hardening & 1.07 & softening & 0.070 & softening \\
6261 & hardening & 1.09 & softening & 0.025 & softening \\
6351 & softening & 1.07 & softening & 0.022 & softening \\
2205 & softening & 1.44 & hardening & 0.056 & softening \\
2507 & hardening & 1.41 & hardening & 0.062 & softening \\
M200 & hardening & 1.33 & mixed & 0.160 & mixed \\
M300 & mixed & 1.23 & mixed & 0.069 & softening \\
M400 & mixed & 1.26 & mixed & 0.062 & softening \\
M450 & mixed & 1.24 & mixed & 0.064 & softening \\
M500 & mixed & 1.27 & mixed & 0.094 & softening \\
M550 & mixed & 1.30 & mixed & 0.136 & mixed \\
M600 & & 1.21 & mixed & 0.069 & softening \\
\hline
\end{tabular}


However, the estimations for A356.0 cast aluminum alloy (Figure $2 b$ ) present longer lifes than experimental results at any load level; this also occurs for the wrought aluminum alloys AA626I-T6 and AA635I-T6 and for the martensitic stainless steel tempered at $200^{\circ} \mathrm{C}$. Duplex stainless steels, on the other hand, have shorter estimated fatigue lifes if they are compared to experimental results; Figure 3a illustrates this behavior for UNS S3 I 803 duplex stainless steel.

The modified four-point method (4PM) presents the worst estimation for cast aluminum alloy $\mathrm{A} 4 \mathrm{I} 3.0$ and martensitic stainless steel tempered at $600^{\circ} \mathrm{C}$ (Figure $3 \mathrm{~b}$ ). For those two materials, $\mathrm{BS}_{\mathrm{N}}$ and MUS methods leads to strain-life curves higher than experimental results for a fatigue life up to $10^{4}$ cycles, and for longer fatigue lifes, sub-estimation of fatigue strength occurs some methods leads to lifes than experimental results at any load level; the other methods super-estimate fatigue life.
A simple statistical evaluation, like the correlation coefficients $\left(R^{2}\right)$ between experimental data and estimated values, presents satisfactory results; if all materials are considered, with strain-life curves estimated in a life range from $10^{2}$ to $10^{7}$ by the seven studied methods, the mean correlation factor of all analysis is $\left(R^{2}=0.98 \pm 0.02\right)$. The lowest correlation factors occur for the $4 \mathrm{P}\left(\mathrm{R}^{2}=0.79\right)$ and 4PM $\left(R^{2}=0.87\right)$ methods applied to the cast aluminum alloy A413.0, and for the 4PM method applied to the AA7 I 75-TI wrought aluminum alloy $\left(R^{2}=0.85\right)$. However, the correlation factors does not show with accuracy the poor fit between experimental and estimated strain-life curves illustrated at FigureS 2 and 3 . Despite those general observations, UNS 542000 tempered at $300^{\circ} \mathrm{C}, 400^{\circ} \mathrm{C}$, $450^{\circ} \mathrm{C}$ (Figure 4) or $500^{\circ} \mathrm{C}$ can be estimated by Bäumel-Seeger method with good accuracy.
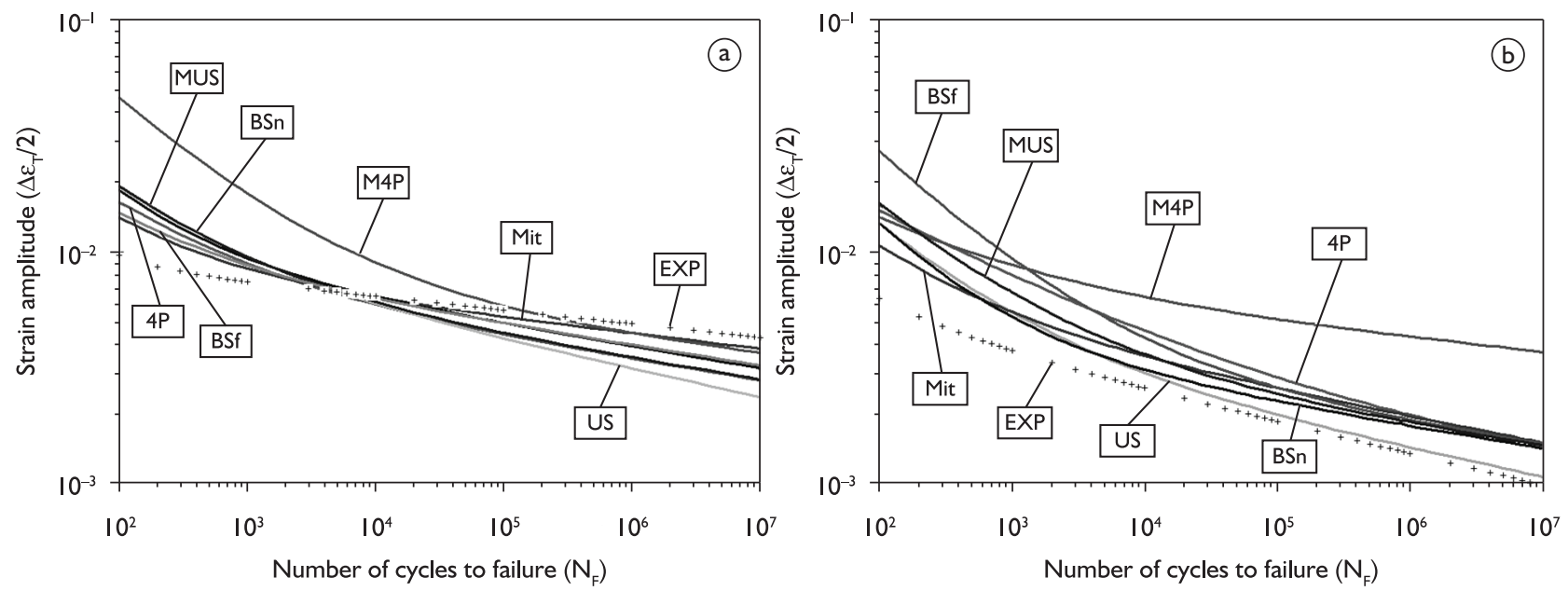

Figure 2. Experimental and estimated strain-life curves for: a) wrought aluminum alloy AA7I 75-TI and b) cast aluminum alloy A356.0.
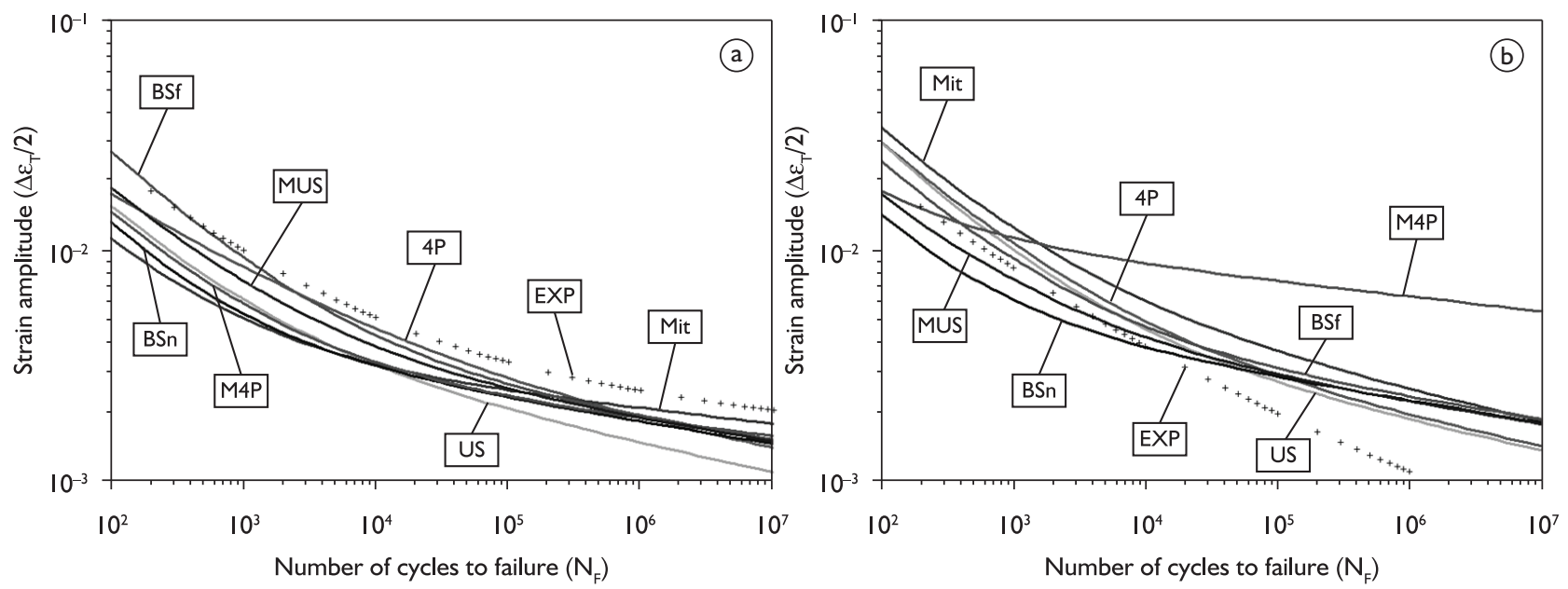

Figure 3. Experimental and estimated strain-life curves for: a) duplex stainless steel UNS S3 I 803 and b) martensitic stainless steel UNS S42000 tempered at $600^{\circ} \mathrm{C}$. 
Equation 39 allows the determination of a strain amplitude variation (SAV), by the comparison of experimental strain amplitude for a given fatigue life $\left(\Delta \varepsilon_{\text {EXP }}\right)$

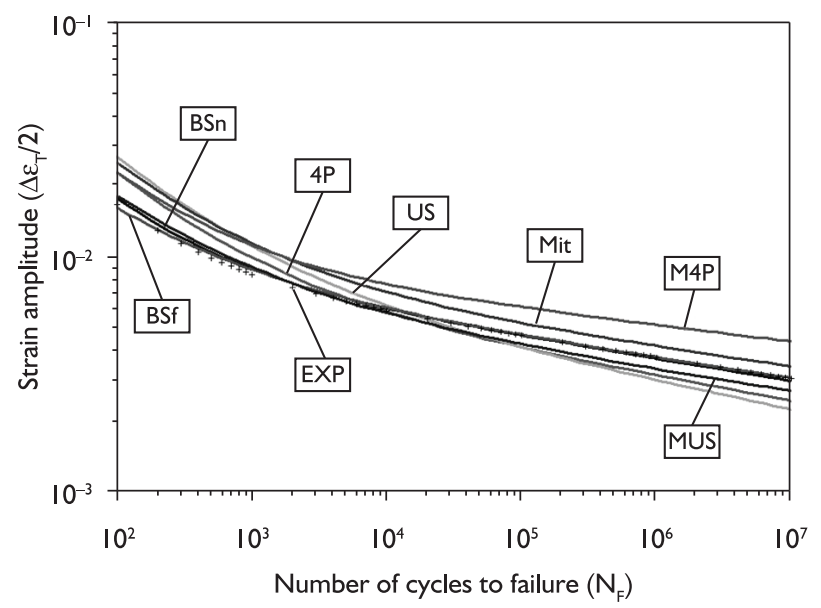

Figure 4. Experimental and estimated strain-life curves for martensitic stainless steel UNS $\$ 42000$ tempered at $450^{\circ} \mathrm{C}$.

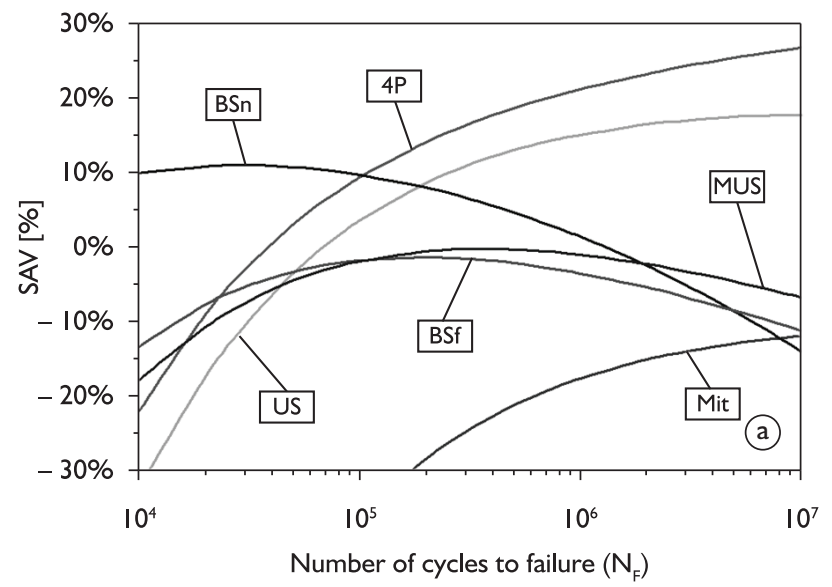

and the estimated (or calculated) strain amplitude for a given fatigue life $\left(\Delta \varepsilon_{\text {CALC }}\right)$. Figures 5 and 6 show SAV of the seven estimation methods for wrought aluminum alloy AA635I-T6, cast aluminum alloy A4I3.0, and martensitic stainless steel UNS $\$ 42000$ tempered at $200^{\circ} \mathrm{C}$ or $450^{\circ} \mathrm{C}$ :

$$
\mathrm{SAV}=\frac{\Delta \varepsilon_{\mathrm{EXP}}-\Delta \varepsilon_{\mathrm{CALC}}}{\Delta \varepsilon_{\mathrm{EXP}}} \cdot 100
$$

For the wrought aluminum alloy AA635I-T6 (Figure $5 \mathrm{a}$ ), $\mathrm{BS}_{\mathrm{F}}$ and MUS methods show the lowest and most stable SAV (approximately 10\%, in a conservative analysis). However, the observed variations does not present the same SAV, for any method, in all the analyzed fatigue life ( $10^{4}$ to $10^{7}$ cycles); the estimation of fatigue life, in this sense, will depend on the material, desired fatigue life and chosen method, which do not characterizing an accurate estimation of fatigue parameters.

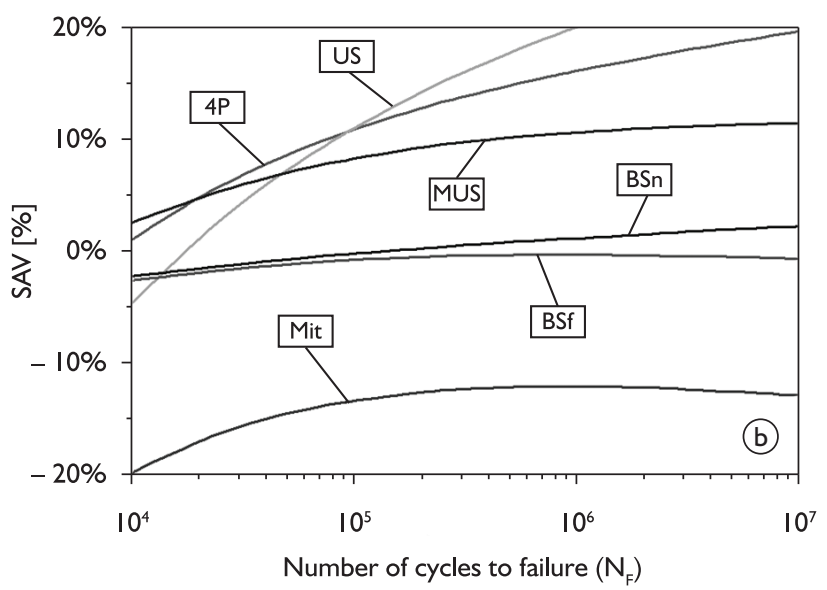

Figure 5. Strain amplitude variation (SAV) between experimental and estimated strain amplitude at specific fatigue lifes for: a) wrought aluminum alloy AA635I-T6 and b) martensitic stainless steel UNS $\$ 42000$ tempered at $450^{\circ} \mathrm{C}$.
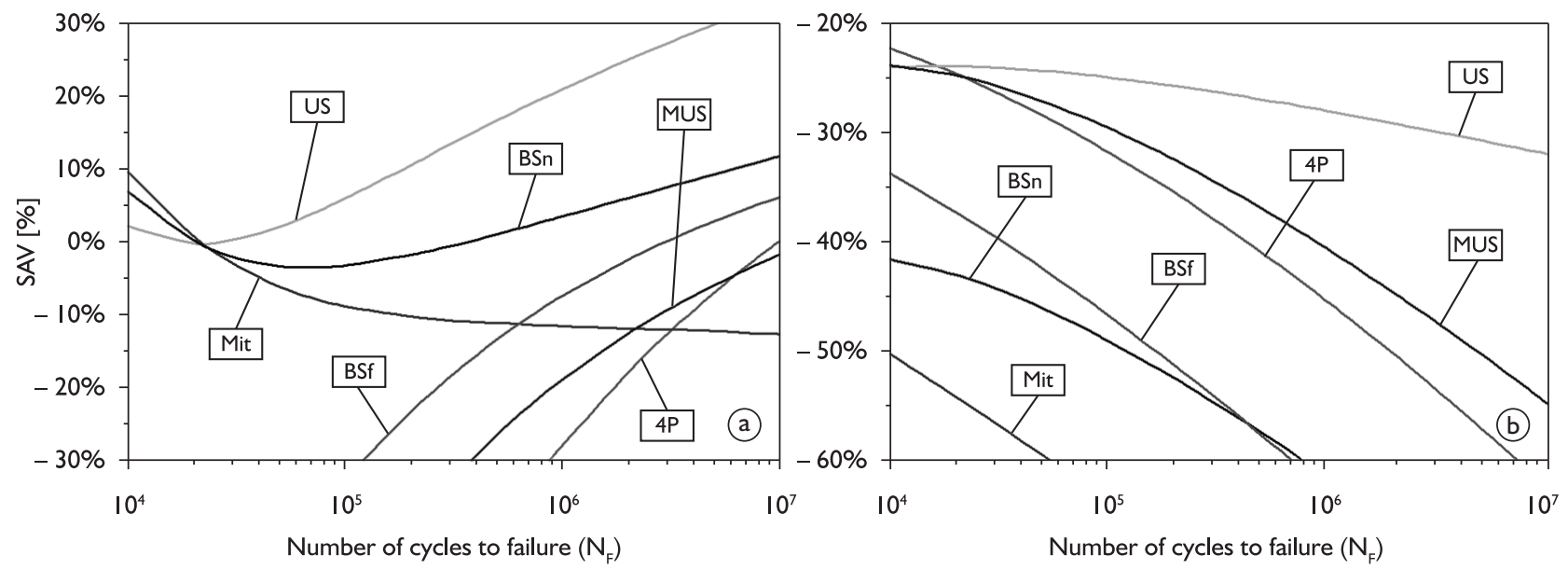

Figure 6. Strain amplitude variation (SAV) between experimental and estimated strain amplitude at specific fatigue lifes for: a) cast aluminum alloy A4I 3.0 and b) martensitic stainless steel UNS $\$ 42000$ tempered at $200^{\circ} \mathrm{C}$. 
Figure 5b, however, shows that strain amplitudes for the martensitic stainless steel UNS S42000 tempered at $450^{\circ} \mathrm{C}$ estimated by $\mathrm{BS}_{\mathrm{N}}$ and $\mathrm{BS}_{\mathrm{F}}$ methods present stable SAV values, below $3 \%$. Equivalent results are obtained for the same methods for the UNS $\$ 42000$ tempered between $300^{\circ} \mathrm{C}$ and $500^{\circ} \mathrm{C}$. Nevertheless, the same steel tempered at $200^{\circ} \mathrm{C}$ (Figure $6 \mathrm{~b}$ ) and $600^{\circ} \mathrm{C}$ presents large deviations from experimental results, considering all the estimation methods, showing that there is not a secure option to estimate fatigue parameters for this steel.

The lack of a stable SAV for a specific material-method combination is clearly noted in Figure 6a for the cast aluminum alloy A4I3.0, and the same behavior could be noted for the wrought aluminum alloy AA626I-T6 and for the duplex stainless steels UNS S3I803 and UNS S32750. Analyzing all those facts, it can be concluded that none of the evaluated estimation methods can describe the fatigue behavior of a material group. However, UNS S42000 tempered at $300^{\circ} \mathrm{C}, 400^{\circ} \mathrm{C}, 450^{\circ} \mathrm{C}$ (Figure 5b) or $500^{\circ} \mathrm{C}$ can be estimated by Bäumel-Seeger method with good accuracy, confirming what is shown by Figure 4 .
Table 7 and Figurel show that the monotonic and cyclic mechanical behaviors are not equivalent, and this is the most probable reason for the absence of a reliable estimation method of fatigue behavior from monotonic properties. The microstrutural changes imposed during cyclic loading deformation, which will lead to the fatigue failure, does not find an equivalent in the monotonic deformation imposed at tension tests, and this could restrain the use of methods for estimation of fatigue behavior from monotonic properties in a more generalized case.

\section{CONCLUSIONS}

After applying seven different estimation methods at 14 material conditions, this work shows that strain amplitude at a given fatigue life can be estimated with good accuracy only by the Bäumel-Seeger method for the martensitic stainless steel UNS S42000 tempered at $300^{\circ} \mathrm{C}, 400^{\circ} \mathrm{C}, 450^{\circ} \mathrm{C}$ or $500^{\circ} \mathrm{C}$. The differences between mechanical behavior during monotonic and cyclic loading are probably the reason for the absence of a reliable method for estimation of fatigue behavior from monotonic properties for a group of materials.

\section{REFERENCES}

I SALERNO, G.; R. MAGNABOSCO, R.; MOURA NETO, C. Mean strain influence in low cycle fatigue behavior of AA7I 75-TI aluminum alloy. International Journal of Fatigue, v. 29, n. 5, p. 829-35, May 2007. http://dx.doi. org/I0.1016/j.ijfatigue.2006.09.004

2 HERTZBERG, R. W.. Cyclic stress and strain fatigue. In: materials. 4. ed., New York: John Wiley \& Sons, 1996. p. 521-78.

. Deformation and fracture mechanics of engineering

3 PARK, J. H.; SONG, J. H. Detailed evaluation of methods for estimation of fatigue properties. International Journal of Fatigue, v. 17, n. 5, p. 365-72, 1995. http://dx.doi.org/10.1016/0142-II23(95)99737-U

4 FONSECA JUNIOR, T. M. I. Métodos de previsão da curva deformação: vida em fadiga para as ligas de alumínio AA626I-T6 e AA635I-T6. 2003. 96 p. Dissertation (Master in Mechanical Engineering) - Mechanical Engineering Faculty, Universidade Estadual de Campinas, Campinas, SP, Brazil, 2003.

$5 \mathrm{ONG}, \mathrm{J}$. H. An improved technique for the prediction of axial fatigue life from tensile data. International Journal of Fatigue, v. I5, n. 3, p. 213-9, 1993. http://dx.doi.org/10.1016/0I42-II23(93)90179-T

$6 \mathrm{ONG}, \mathrm{J} . \mathrm{H}$. An evaluation of existing methods for the prediction of axial fatigue life from tensile data. International Journal of Fatigue, v. I5, n. I, p. 13-9, 1993. http://dx.doi.org/I0.1016/0I42-II23(93)9007I-W

7 MORROW, J. Cyclic plastic strain energy and fatigue of metals. West Conshohocken: ASTM International, 1965. (STP 378)

8 AMERICAN SOCIETY FOR TESTING AND MATERIALS. E 8M - 04: Tension testing of metallic materials. West Conshohocken, 2004.

9 AMERICAN SOCIETY FOR TESTING AND MATERIALS. E 606 - 92: Strain-controlled fatigue testing. West Conshohocken, 1992.

I0 MITCHELL, M. R. Fatigue analysis for design. In: SEMINAR ON FATIGUE, I., 2000, São Bernardo do Campo. Proceedings... São Bernardo do Campo: SAE Brazil, 2000. p. 5- 12.

II RIBEIRO, A. S.; COSTA J. D.; FERNANDES, A. A. Fadiga oligocíclica: propriedades cíclicas da liga de alumínio Al 606I-T65I. In: COBEM - BRAZILIAN CONGRESS OF MECHANICAL ENGINEERING, I5., 1999, Águas de Lindóia. Proceedings... Campinas: ABCM, 1999.

Recebido em: 10/10/2011

Aceito em: 24/09/2012 


\section{LIST OF SYMBOLS}

$\Delta \varepsilon_{\mathrm{E}} / 2$ - Elastic strain amplitude

$\Delta \varepsilon_{\mathrm{p}} / 2$ - Plastic strain amplitude

$\Delta \varepsilon_{T} / 2$ - Total strain amplitude applied during cyclic loading

$\varepsilon$ - Total strain applied during monotonic loading

$\varepsilon_{\mathrm{E}}$ - Elastic strain

$\varepsilon_{\mathrm{p}}$ - Plastic strain

$\varepsilon_{\mathrm{F}}$ - True fracture strain

4P - Four-point method

4PM - Modified four-point method

$A R$ - Area reduction at fracture

$\mathrm{b}$ - Fatigue strength exponent

$\mathrm{BS}_{\mathrm{F}}$-Bäumel-Seeger method for ferrous materials

$B_{N}-$ Bäumel-Seeger method for non-ferrous alloys

$C$ - Fatigue strain exponent

$\mathrm{C}_{\mathrm{E}}$ - Elastic coefficient

$C_{p}$ - Plastic coefficient

$\mathrm{E}$ - Young's modulus

$\mathrm{H}$ - Strength coefficient of the Ramberg-Osgood equation

$H^{\prime}$ - Cyclic strength coefficient

Mit - Mitchell method

MUS - Modified universal slopes method

$\mathrm{n}$ - Strain-hardening exponent of the Ramberg-Osgood equation

n' - Cyclic strain-hardening exponent

$\mathrm{N}_{\mathrm{F}}$ - Number of cycles to failure

SAV - Strain amplitude variation

$\sigma-$ Stress applied during monotonic loading

$\sigma_{\mathrm{F}}-$ True fracture stress

$\mathrm{TE}$ - Total elongation

$\mathrm{TE}^{25}$ - Total elongation in $25 \mathrm{~mm}$

$\mathrm{T}_{\mathrm{s}}$ - Ultimate tensile strength

US - Universal slopes method

$\mathrm{Y}_{\mathrm{S}}-$ Yield strength 